\title{
JORNADAS DE TRABALHO DE MULHERES E HOMENS EM UM ASSENTAMENTO DO MST
}

\author{
GIOVANA ILKA JACINTO SALVARO
}

Universidade Federal de Santa Catarina

Resumo: Este texto busca discutir a divisão do trabalho em um assentamento coletivo do Movimento dos Trabalhadores Rurais Sem Terra (MST), em Santa Catarina, marcado pela proposta de coletivização da terra e dos meios de produção. Nessa forma de organização, busca-se, seguindo as diretrizes estabelecidas pelo MST, a transformação igualitária e solidária da sociedade, incluindo a construção de novas relações de gênero. O que se observou é que, no cotidiano, mulheres e homens, sujeitos históricos e culturais, apropriam-se desses discursos de gênero, ao mesmo tempo que buscam lidar com as contradições que se apresentam. Entre estas, colocam-se as diferentes jornadas de trabalho que, apoiadas em padrões relacionais fixos, determinam oito horas diárias para os homens na produção e quatro para as mulheres, em função do trabalho doméstico e do cuidado das crianças.

Palovras-chave: assentamento coletivo, relações de gênero, divisão sexual do trabalho, jornadas diárias de trabalho.

Este texto refere-se ao estudo realizado em 2003 no assentamento coletivo Sepé Tiaraju, organizado pelo Movimento dos Trabalhadores Rurais Sem Terra (MST), em Santa Catarina, quando da realização de minha dissertação de mestrado. ${ }^{1}$ Seguindo os pressupostos teóricos da psicologia histórico-cultural, fundada por Vygotski, e de autoras/ es $^{2}$ que discutem as temáticas gênero e trabalho, meu interesse esteve centrado nas atividades desempenhadas por mulheres e homens no assentamento. Por meio de entrevistas abertas e observações, busquei, no cotidiano das vivências singulares e coletivas desses sujeitos, investigar os sentidos produzidos sobre a divisão sexual do trabalho.

\footnotetext{
Copyright @ 2004 by Revista Estudos Feministas

1 Dissertação defendida em fevereiro de 2004 junto ao Programa de Pós-Graduação em Psicologia da Universidade Federal de Santa Catarina, na linha de pesquisa "Práticas sociais e constituição do sujeito", sob a orientação da Profa Dra Mara Coelho de Souza Lago (SALVARO, 2004).

${ }^{2}$ Cristina BRUSCHINI, 1982 e 1993; Elisabeth SOUZA-LOBO, 1991; Heleieth SAFFIOTI, [s/d] e 1992; Tania FONSECA, 2000; Mara LAGO, 1986; Maria Ignez PAULILO, 1986 e 2000; Paola GIULANI, 1997; Auri CUNHA, 1998; Noëlle LECHAT, 1993 e 1996, entre outras/os.
} 
Na perspectiva teórica seguida, o processo de significação, formado pelos signos produzidos e apropriados histórica e culturalmente pelos sujeitos, é fundante do psiquismo humano. Significados e sentidos compreendem o duplo referencial semântico desse processo. O significado é um sentido público, arbitrário, convencionado coletivamente. 0 sentido, privado, diz respeito à história particular do sujeito, isto é, ao modo singular pelo qual o sujeito se apropria dos significados produzidos coletivamente. Para Vygotski, ${ }^{3}$ a palavra, signo lingüístico por excelência e unidade do pensamento verbal, veicula significados e sentidos.

Uma palavra adquire o seu sentido no contexto em que surge; em contextos diferentes, altera o seu sentido. O significado permanece estável ao longo de todas as alterações do sentido. O significado dicionarizado de uma palavra nada mais é do que uma pedra no edifício do sentido, não passa de uma potencialidade que se realiza de formas diversas na fala. ${ }^{4}$

De acordo com esse referencial, destaco a importância de ter trabalhado com entrevistas nas quais os 21 sujeitos entrevistados relataram suas trajetórias de trabalho no MST. Nesse processo, as relações de trabalho que constituíam o cotidiano do assentamento foram sendo tramadas pelos/as entrevistados/as a partir dos vários fios de suas histórias de vida.

As autoras e autores que tratam das relações de trabalho, gênero e divisão sexual do trabalho, nos estudos utilizados para fundamentar tal pesquisa, com diferentes referenciais epistemológicos, convergem sobre o fato de que o trabalho é generificado, 0 que implica considerar que é valorizado a partir de significados atribuídos histórica e culturalmente ao feminino e ao masculino em contextos sociais específicos. O trabalho generificado é, ao mesmo tempo, produto e produtor de sentidos e significados nos contextos em que ocorrem, no caso deste estudo, no cenário do assentamento coletivo, lugar onde sujeitos concretos se produzem subjetivamente ao produzirem sua existência. No entanto, o assentamento como lugar específico de produção de existência humana está inserido em contextos mais amplos, que incluem as relações sociais que configuram a sociedade em suas diferentes dimensões políticas, econômicas, entre outras.

Entre os desdobramentos que constituem a divisão sexual do trabalho, abordados e discutidos na dissertação, optei, neste texto, por priorizar a discussão acerca das diferentes jornadas diárias de trabalho, que envolvem mulheres e homens, e da sua relação com os discursos produzidos pelo MST, pois considero que tais jornadas suscitam uma discussão interessante, no que se refere ao modo como são concebidas as relações de gênero no assentamento.

\section{Por que estudar a divisão sexual do trabalho em um assentamento coletivo do MST?}

O MST é um movimento reivindicatório, que trata da exclusão dos trabalhadores rurais do acesso à terra, das condições de produção, das desigualdades de classe, mas também defende objetivos referentes à participação igualitária das mulheres nos trabalhos que constituem o cotidiano dos acampamentos e assentamentos. Conta inclusive com um

\footnotetext{
${ }^{3}$ VYGOTSKI, 1987.

${ }^{4}$ VYGOTSKI, 1987, p. 125.
} 
setor de gênero, o qual defende objetivos gerais e específicos que têm como fio condutor a construção de novas relações entre homens e mulheres. ${ }^{5}$

Esses objetivos emergem como uma construção que vem sendo realizada desde a criação do MST, em 1984. Essa construção tem se pautado na idéia de que um movimento social que visa à transformação da sociedade não pode reduzir suas reivindicações à conquista e/ou acesso à terra. ${ }^{6}$ Nessa perspectiva, outras questões referentes às relações entre os sujeitos, entre elas as de gênero, são também discutidas, já que orientam as relações sociais no cotidiano dos assentamentos, assim como na sociedade toda, de modo a se observar que, para o MST, a transformação igualitária e solidária de uma sociedade inclui as relações de gênero. Esses objetivos, tomando a forma de discursos, publicados ou não, são utilizados para promover a organização de acampamentos, dos assentamentos, bem como do movimento.

Pautado em discursos de igualdade e solidariedade, o MST incentiva formas associativas e cooperativas de produção após a conquista da terra, fato que é justificado pela necessidade fundamental da ação coletiva para a viabilização de subsistência digna para as famílias rurais. Nos assentamentos coletivos podem ser evidenciadas peculiaridades, pois, além de se organizarem em torno de modos coletivos de produção, são caracterizados também pela não-divisão da área total de terra em terrenos individuais. Pode-se dizer que esses assentamentos, pautados em ideais de coletivismo, em tese, não contemplam desigualdades e segregações entre os assentados, sejam eles homens ou mulheres, velhos, jovens, crianças, etc.

As relações sociais nos assentamentos, no entanto, como pude observar em estudos de alguns autores e no decorrer da pesquisa, são perpassadas por contradições e limitações que lançam questionamentos acerca do modo coletivista e igualitário de de sua concepção. É nesse ponto que gostaria de inserir e centrar a discussão sobre a divisão sexual do trabalho, especificamente sobre as diferentes jornadas de mulheres e homens em determinadas atividades que constituem o cotidiano de um assentamento coletivo.

\footnotetext{
${ }^{5}$ Cito os objetivos descritos pelo setor de gênero do MST: "Objetivos gerais: a) Levar a discussão de gênero para o conjunto do MST e procurar mostrar a importância de se estabelecer novas relações de gênero para avançar a luta de classes. b) Elevar o nível de participação das mulheres na luta pela terra, pela reforma agrária e na construção de uma nova sociedade. c) Contribuir para transformar as relações de gênero no MST para que homens e mulheres sejam de fato sujeitos sociais. d) Motivar a construção de novas relações na família, militância e instâncias, baseadas em valores com o respeito, solidariedade, igualdade, companheirismo. Objetivos específicos: a) Fortalecer o MST nas suas diversas instâncias e setores. b) Massificar e qualificar a participação das mulheres desde antes do acampamento (na fase de preparação), durante a luta pela terra, nos assentamentos, setores e instâncias. c) Exercer pressão permanente para a construção de novas relações de gênero, baseando-se em novos valores. d) Motivar a construção de um novo jeito de ser família, em que toda a comunidade (núcleos, acampamentos, assentamentos) tenha responsabilidade no processo de educação e formação das crianças e jovens e não apenas os pais biológicos. e) Despertar a mulher para a necessidade de participar das decisões políticas e econômicas, para a importância de assumirem tarefas produtivas e administrativas e serem beneficiadas nos projetos e recursos. f) Fortalecer a auto-estima das mulheres através de atividades de formação específicas. g) Incluir as reivindicações femininas na pauta do MST, como por exemplo: ciranda e educação infantil, reconhecimento da profissão de trabalhadora rural através do cadastro, políticas de saúde específicas para a mulher e a família rural” (MST, 2001, p. 147-148).

${ }^{6}$ Denise MELO, 2001, e Cristiani SILVA, 2003, evidenciaram em seus estudos o modo como o MST incorporou as questões de gênero em suas discussões e reivindicações.
} 


\section{"As mulheres trabalham quatro horas e os homens trabalham oito..."}

A discussão que está na base desse enunciado articula-se, a meu ver, na interface do trabalho considerado produtivo e do trabalho doméstico, em uma dinâmica em que as categorizações produtivo e doméstico não são opostas, mas emergem como relacionais e históricas, constituídas e constitutivas de mulheres e homens nas diferentes sociedades. Conforme Heleieth Saffiotti, quando ressalta a historicidade de categorias analíticas, tais como público e privado, produção e reprodução, trabalho produtivo e trabalho doméstico, alertando para os riscos que podem ocorrer ao pensá-las como opostas e contrárias,

Trata-se, além de categorias de análise, de categorias históricas. E é essa historicidade que deve ser ressaltada e retida, uma vez que ela aponta ostensivamente para a morte de tais construções. Na verdade, não existe apenas o perigo de se tomarem como eternas tais categorias, cuja natureza é profundamente histórica. Este risco não pode ser negado, mas pode ser evitado. Basta, por exemplo, que nos perguntemos desde quando o mundo conhece as noções de público e privado, de produção e reprodução, de trabalho produtivo e trabalho doméstico, etc. São noções extremamente recentes.

Quero ressaltar com isso que não considero essas categorias como dicotômicas e excludentes, bem como não estou tratando de concepções de trabalho produtivo, no modo de produção capitalista, que se refere especificamente à produção de mais-valia que permite a acumulação de capital.

Em estudos sobre o trabalho feminino em diferentes regiões, Maria Ignez Paulilo8 ressalta diferenças presentes em atividades agrícolas realizadas por homens e por mulheres, caracterizadas a partir da classificação de trabalho leve e pesado: atividades leves realizadas pelas mulheres e pelas crianças, e atividades pesadas, pelos homens adultos. A autora argumenta que não se trata da atividade em si, enquanto leve ou pesada, mas esses significados são atribuídos em função do gênero que os realiza. Em artigo no prelo, a autora ${ }^{9}$ retoma a discussão sobre o trabalho leve e pesado, e ressalta sua repetição em relação ao trabalho doméstico e produtivo. Nessa relação, à mulher cabe a realização de tarefas no espaço doméstico.

Na pesquisa realizada no assentamento estudado, ative-me também às mudanças ocorridas por conta da coletização da terra, as quais demonstraram que o trabalho, anteriormente realizado pelos membros da família, no regime de pequena propriedade, passou a ser responsabilidade do grupo de assentados, formado por várias famílias. 0 trabalho na lavoura e na casa também sofreram modificações, pois foram organizados em setores. O assentamento seguia uma organização coletiva no que se refere às relações de trabalho, desde a produção até a comercialização, a educação, saúde, lazer, entre outras relações que o constituíam. Com exceção das casas, todos os espaços do assentamento eram de uso coletivo. As assentadas e os assentados buscavam seguir as diretrizes propostas pelo MST para coletivos, o que conferia ao assentamento uma certa semelhança em relações aos demais, sem esquecer que era também um espaço singular, produção de sujeitos históricos e culturais, em suas práticas cotidianas.

A organização do assentamento ocorria por meio de uma direção geral, três núcleos de base e seis setores que compreendiam lavoura; gado (leite para venda, consumo e

\footnotetext{
7 SAFFIOTI, 1992, p. 101.

${ }^{8}$ PAULILO, 1986.

${ }^{9}$ PAULILO, no prelo.
} 
corte); subsistência (horta comunitária e demais produções destinadas ao consumo interno); integração (criação de suínos para agroindústrias em sistema de contratação de trabalho); administração; social (saúde, educação, lazer, mística, ${ }^{10}$ embelezamento).

Tendo em vista as diretrizes propostas pelo MST na organização/divisão do trabalho no assentamento, segundo uma das assentadas, buscou-se incorporar também as discussões de gênero produzidas pelo movimento, em especial as que se referiam à colocação de mulheres como coordenadoras de núcleos de base juntamente com os homens, espaços estes destinados às discussões organizativas e políticas do assentamento, e constituídos a partir da participação de todas as famílias. Como referido em um dos documentos produzidos pelo movimento,

para nós do MST, a coordenação do núcleo deverá ser necessariamente compartilhada em pé de igualdade por um homem e por uma mulher, escolhidos por todos os membros do núcleo [...] Os dois coordenadores (um homem e uma mulher) é uma opção política que o MST faz de muita importância para a vida do assentamento. Em geral, o assentamento é comandado pelos homens, sob um olhar masculino da vida, o que limita a compreensão do conjunto do assentamento. A presença feminina na direção e coordenação do assentamento é um esforço que cabe a todos realizar, buscando qualificar estas coordenações para apreender a realidade do assentamento como um todo. ${ }^{11}$

Foi possível constatar que de fato mulheres e homens coordenavam os núcleos, assim como integravam os setores e cumpriam determinadas horas diárias de trabalho, que eram convertidas em alimentos para o consumo interno e em dinheiro resultante da comercialização externa da produção. As horas trabalhadas tinham o mesmo valor de troca para mulheres e homens. Mas, nesse sistema de conversão, as horas despendidas para reuniões dos núcleos, direção e planejamentos dos setores não eram incluídas. Isso sugere que as concepções do que é, ou não, considerado trabalho orientavam esse sistema. Algo que, de certo modo, definia e categorizava como trabalho somente o que resultava em produção para a subsistência ou comercialização, além do trabalho da educadora, que recebia salário da prefeitura municipal, como professora concursada. Os próprios cuidados de saúde proporcionados por uma das assentadas não resultavam em horas computadas na sua jornada de trabalho.

Além de as mulheres e de os homens não cumprirem as mesmas jornadas diárias, passíveis de serem convertidas em alimentos e/ou dinheiro, percebi, em meio aos discursos acerca das relações de gênero que permeavam a organização/divisão sexual do trabalho no assentamento, que esses sujeitos também não integravam os setores do mesmo modo. Havia predominância das mulheres nos setores social e de subsistência, os quais eram constituídos por atividades nas áreas da saúde, educação, lazer, embelezamento e produção de alimentos destinados ao consumo interno, consideradas tradicionalmente como femininas. Por um lado, o trabalho das mulheres e dos homens no assentamento e suas diferentes jornadas diárias, quatro horas para elas e oito para eles, foram utilizados por algumas das assentadas para justificar sua predominância nesses setores. Por outro lado, as diferentes jornadas de trabalho se apresentaram, para as mulheres, como possibilidade de conciliar os trabalhos domésticos e o cuidado dos filhos, como evidencia o relato de Silvia, uma das assentadas que entrevistei:

[Quais são os trabalhos que você faz?] Tem o trabalho da lavoura. São todos os trabalhos, limpa de planta, colheita. Também as mulheres trabalham no setor de subsistência, até por

${ }^{10}$ Sobre as místicas, conferir Alícia CASTELLS, 2001.

"MST, 2001, p. 84-85. 
ser mais perto. Porque hoje nós tamo fazendo quatro horas por dia. Pela ciranda ${ }^{12}$ e até para conseguir dar conta do trabalho de casa. As crianças vão para aula em horários diferenciados. Uns vão de manhã, uns vão à tarde. Então, precisa acompanhar também. Então, a gente tá fazendo quatro horas. A gente procura trabalhar pelo menos mais perto, porque daí a gente tá conseguindo também vencer o trabalho de casa (Silvia, 32 anos).

Essa fala sugere que a dupla jornada de trabalho feminina, em que as mulheres agregam às tarefas extradomésticas as tarefas domésticas, mantém-se inalterada no assentamento coletivo, evidenciando com isso que a divisão sexual do trabalho na família não sofreu modificações significativas. Essa questão fica ainda mais evidente com a observação de que alguns arranjos foram necessários por conta do cuidado das crianças e demais tarefas na esfera doméstica. Esse cuidado, mesmo que não direto, por parte do grupo, acaba sendo também uma preocupação coletiva, à medida que os trabalhos são organizados de modo que as mulheres possam agregar tais tarefas. Isso implica, também para os homens, um maior acúmulo de tarefas. Outros estudos realizados sobre o MST evidenciaram esses arranjos coletivos em relação ao cuidado das crianças.

O cuidado das crianças, preocupação normalmente feminina, passa a ser do conjunto dos sócios que, nas normas estabelecidas de comum acordo, definem também o horário de trabalho das mulheres com filhos pequenos.

É importante destacar que, apesar da responsabilidade e arranjos coletivos no que se refere ao cuidado das crianças, as cuidadoras ainda são as mulheres, não somente pelo fato de as mulheres serem 'liberadas' do trabalho nos setores para cuidar das crianças em casa, mas porque o trabalho da ciranda infantil, que integra o setor social, também é realizado por mulheres. Além disso, a própria criação da ciranda se fez pela possibilidade de 'liberar' as mulheres e não os homens para o trabalho considerado produtivo. Mesmo que a divisão do trabalho seja uma discussão travada no âmbito do coletivo, entre mulheres e homens, são poucos os questionamentos sobre o pressuposto de que 'cuidar de' é uma responsabilidade feminina. citado:

Conforme um dos objetivos do setor de gênero, definido no documento do MST já

d) Organizar a ciranda infantil: também deveremos discutir com as famílias do assentamento a necessidade da ciranda infantil para crianças de 0 a 6 anos. Este espaço, além de criar condições para a participação das mulheres no processo produtivo do assentamento, também proporciona espaços de socialização e educação coletiva das crianças pequenas. ${ }^{14}$

Como pontuei, não há um único discurso com relação a isso. Enquanto algumas falas naturalizaram o papel das mulheres como cuidadoras, emergiram outras que questionaram a existência de um único jeito de ser pai e mãe, bem como os padrões rígidos que regem a divisão do trabalho entre homens e mulheres, especialmente no que se refere ao fato de a ciranda infantil ser um local de trabalho feminino. Cecília, uma assentada que mora no assentamento desde sua implantação, pontuou que "sempre sobra

\footnotetext{
${ }^{12}$ Ciranda infanti é um espaço que deve ser organizado em eventos, instâncias e ocasiões onde estiverem presentes as crianças de zero a seis anos:"d) Organizar a ciranda infantil: também deveremos discutir com as famílias do assentamento a necessidade da ciranda infantil para as crianças de 0 a 6 anos. Este espaço, além de criar condições para a participação das mulheres no processo produtivo do assentamento, também proporciona espaços de socialização e educação coletiva das crianças pequenas" (MST, 2001, p. 96).

${ }^{13}$ Dulcinéia PAVAN, 1998, p. 107.

14 MST, 2001 , p. 96.
} 
pra mulher, né?" (Cecília, 33 anos). Cecília pareceu questionar o que se naturalizou como trabalho das mulheres. O fato de o setor social, especificamente da ciranda infantil, ser um trabalho realizado por mulheres, também foi questionado por Mário, outro assentado que também mora no assentamento desde o início, quando lhe perguntei a respeito da divisão sexual do trabalho:

o setor social, até mesmo é um erro, do grupo no geral, e também do setor, que no momento que vai ter uma ciranda, cuidar as crianças, normalmente, se procura as mulheres [...] para cuidar as crianças. Agora, não é uma culpa do setor social e nem culpa das mulheres. É uma culpa do grupo inteiro, não fazer a discussão. Se o homem pode contribuir, porque, normalmente, talvez, a gente tenha que ficar alguém, principalmente a administração, fazendo alguns serviços dentro da agrovila [...] e que o trabalho para ele depois fica muito longe, ele contribuir no trabalho, o restante do dia. Ele poderia contribuir, talvez, na ciranda, dando condições pras mulheres. Então, a gente não fez essa discussão, ainda. Ainda tá com o processo de a gente avançar. Mas alguns passos, a gente já deu com relação a isso (Mário, 28 anos).

O relato de Mário, além de questionar alguns padrões socialmente estabelecidos acerca da organização do trabalho, pontua que ainda é necessário avançar no que se refere às relações de gênero. O sentido de avançar, nesse caso, parece estar colocado como possibilidade de 'superação' de uma dada realidade. Responsabiliza o grupo todo pela não- discussão sobre o fato de o setor social ser predominantemente feminino. Assim, desloca o que considera problemático e que precisa ser superado para o campo relacional. Considerar o gênero enquanto relacional e não como atributo de uma pessoa, como enfatiza Heleieth Saffioti,

é fundamental para demarcar o campo de batalha e identificar o adversário. Nestas circunstâncias, o inimigo da mulher não é o homem nem enquanto indivíduo, nem como categoria social, embora seja personificado por ele. O alvo a atacar passa a ser, numa concepção relacional, o padrão dominante de relação de gênero. ${ }^{15}$

Ainda sobre o cuidado das crianças, apontado como um dos desencadeadores das diferentes jornadas de trabalho, os questionamentos feitos por Cecília e Mário evidenciaram mudanças em curso. Os estudos realizados por Maria Juracy Toneli Siqueira contribuem para pensar essa questão:

Tenho trabalhado nos últimos anos com homens que 'maternam' ${ }^{16}$ e que participam de cenas como as que relatei no início deste trecho. Trata-se de homens de vários segmentos sociais, com níveis de escolaridade e padrões de vida bastante diferentes entre si. Alguns decidiram criar seus filhos sozinhos, após a separação. Outros, premidos pela necessidade de sobrevivência da família e acesso da mulher a algum emprego, dedicam-se às tarefas domésticas e aos cuidados dos filhos. Outros, ainda, mesmo com a figura feminina em casa, optam por uma participação mais ativa no âmbito doméstico e na educação das crianças. Enfim, os motivos e circunstâncias envolvidas são de ordens distintas. ${ }^{17}$

Nesse sentido, o trabalho das mulheres nos setores não ocorre em tempo integral no assentamento estudado, em função da necessidade explicitada de conciliarem os trabalhos nos referidos setores com o trabalho no espaço doméstico e o cuidado dos filhos. Isso

${ }^{15}$ SAFFIOTI, 1994, p. 275-276.

${ }^{16}$ Nota elaborada pela autora: "Maternagem aqui refere-se às atitudes de 'cuidar de', tradicionalmente, atribuídas às mulheres. Não se trata, portanto, de sinônimo de maternidade e, tampouco, de um atributo biológico/essencial das mulheres. São atitudes social e historicamente construídas" (SIQUEIRA, 1999, p. 199). 17 SIQUEIRA, 1999, p. 193. 
sugere que, no que se refere ao trabalho doméstico, não havia uma divisão que contemplasse também o trabalho dos homens. No entanto, entre alguns casais mais jovens, com filhos pequenos, foi possível observar os homens dividindo com as mulheres a preparação dos alimentos, a lavagem de louça, a alimentação e o banho das crianças.

Sobre as relações entre o trabalho doméstico e os trabalhos em outras esferas, consideradas produtivas, Helena Hirata, em pesquisas comparativas no Brasil, no Japão e na França sobre o trabalho urbano, contribui para se pensar essa articulação. A autora ressalta "uma correspondência entre a hierarquia na família, na profissão e na sociedade que produz configurações extremamente diferentes nos status sociais e nas relações de poder". ${ }^{18}$ Essas comparações, por sua vez, indicaram a importância de se considerar a divisão sexual do trabalho doméstico, familiar e profissional, para se pensar a própria organização industrial. Com isso se enfatiza que o conceito de trabalho deve incorporar o trabalho doméstico, assalariado e não assalariado.

Dessa forma, penso que no assentamento fica clara a impossibilidade e/ou limitação de analisar as atividades realizadas nos setores e as diferentes jornadas de trabalho atribuídas aos homens e às mulheres, sem considerar os afazeres domésticos. É importante destacar que a constatação da possível naturalização de uma cadeia de interdependência entre essas esferas abre possibilidades para se pensar a imposição de um padrão relacional que impossibilita a abertura para outras formas de conceber a divisão sexual do trabalho.

Por um lado, penso que outras questões estão em jogo, como por exemplo a valorização do trabalho nos setores, em detrimento do trabalho doméstico. Maria Rua e Miriam Abramovay, em pesquisa realizada sobre as relações de gênero em assentamentos rurais, constataram, por meio das falas de homens e mulheres assentados, que cabe às mulheres os trabalhos de cozinhar, limpar a casa, lavar a roupa, cuidar de crianças e de velhos enfermos. Segundo as autoras,

historicamente essas tarefas são menosprezadas porque estão fora do circuito mercantil e consagram uma certa divisão sexual e social do trabalho, que segmenta atividades produtivas e reprodutivas.

Por outro lado, cria-se a necessidade, por conta de uma busca de igualdade, de as mulheres e de os homens terem de fazer 'tudo de tudo' no assentamento. A pergunta que se pode fazer é se isso de fato é necessário e/ou contribui ainda mais para aumentar as desigualdades, à medida que provoca uma certa homogeneização do próprio fazer. Desse modo, a igualdade de gênero, tal como está colocada nos objetivos do MST e apropriada pelos/as assentados/as, parece não abrigar as diferenças entre homens e mulheres, e entre sujeitos singulares.

\section{Referências bibliográficas}

BRUSCHINI, Cristina. "A mulher e o trabalho". In: BRUSCHINI, Cristina; ROSEMBERG Fúlvia (Orgs.). Trabalhadoras do Brasil. São Paulo: Brasiliense/Fundação Carlos Chagas, 1982. p. 9-22. . "Trabalho feminino: trajetória de um tema, perspectivas para o futuro". In: XVII ENCONTRO ANUAL DA ANPOCS, 17, 1993, Caxambu, MG. Anais... Caxambu, 1994.

CASTELLS, Alícia. A criatividade dos sem-terra na construção do habitat: um olhar etnográfico sobre a dimensão especial do MST. 2001. Tese (Doutorado Interdisciplinar em Ciências Humanas) - Universidade Estadual de Campinas, Campinas.

${ }^{18}$ HIRATA, 2002, p. 286.

19 RUA E ABRAMOVAY, 2000, p. 168. 
CUNHA, Auri D. C. "Relações de gênero na agricultura familiar no perímetro irrigado de São Gonçalo (PB)". In: BRUSCHINI, Cristina; HOLLANDA, Heloísa B. de (Orgs.). Horizontes plurais: novos estudos de gênero no Brasil. São Paulo: FCC; Ed. 34, 1998. p.195-224.

FONSECA, Tania M. G. Gênero, subjetividade e trabalho. Petropólis, RJ: Vozes, 2000.

GIULANI, Paola C. "Os movimentos de trabalhadoras e a sociedade brasileira". In: DEL PRIORE Mary (Org.). História das mulheres no Brasil. Coordenadora de textos: Carla Bassanezi. São Paulo: Contexto, 1997. p. 640-667.

HIRATA, Helena. Nova divisão sexual do trabalho?: um olhar voltado para a empresa e a sociedade. São Paulo: Boitempo Editorial, 2002.

LAGO, Mara C. S. "Trabalho feminino, trabalho improdutivo?" Revista de Ciências Humanas, Florianópolis, n. 8, p.129-133, 1986.

LECHAT, Noëlle M. P. A questão de gênero no Movimento dos Trabalhadores Rurais Sem Terra (MST): estudo de dois assentamentos no Rio Grande do Sul. 1993. Dissertação (Mestrado em Antropologia Social) - Universidade Estadual de Campinas, Campinas.

- "Relações de gênero em assentamentos do Movimento do MST (RS): a participação da mulher na produção e reprodução em unidades familiares e coletivas". In: PRESVELEU, Clio; ALMEIDA, Francesca Rodrigues; ALMEIDA, Joaquim Anécio. Mulher, família e desenvolvimento rural. Santa Maria: Ed. da UFSM, 1996. p. 93-116.

MELO, Denise, M. A construção da subjetividade de mulheres assentadas pelo MST. 2001. Dissertação (Mestrado em Educação) - Universidade Estadual de Campinas, Campinas. MST. Construindo caminho. São Paulo: Movimento dos Trabalhadores Rurais Sem Terra (MST), 2001.

PAULILO, Maria Ignez S. "O peso do trabalho leve". In: GRASSI, Estela (Comp.). La antropologia social y los estudios de la mujer. Buenos Aires: Humanitas, 1986. p. 135-148.

. Terra à vista ... e ao longe. 2. ed. Florianópolis: Ed. da UFSC, 1998.

"Movimento de mulheres agricultoras: terra e matrimônio". Cadernos de Pesquisa, Florianópolis: PPGSP/UFSC, v. 21, n. 1, p.1-15, 2000.

. Trabalho familiar: uma categoria esquecida de análise. No prelo.

PAVAN, Dulcinéia. As Marias Sem Terras: trajetória e experiências de vida de mulheres assentadas em Promissão - SP - 1985/1996. 1998. Dissertação (Mestrado em História Social) - Pontifícia Universidade Católica de São Paulo, São Paulo.

RUA, Maria; ABRAMOVAY, Miriam. Companheiras de luta ou "coordenadoras de panelas"? As relações de gênero nos assentamentos rurais. Brasília: UNESCO, 2000.

SAFFIOTI, Heleieth I. B. "Trabalho visível e trabalho invisível". Revista Ciência e Cultura, n. ..., p. ......, s/d.

. "Reminiscências, releituras, reconceituações". Revista Estudos Feministas, n. 0, p. 97103, 1992.

. "Posfácio: conceituando gênero". In: SAFFIOTI, Heleieth I. B.; MUÑOZ-VARGAS (Orgs.). Mulher brasileira é assim. Rio de Janeiro: Rosa dos Tempos/NIPAS; Brasília: UNICEF, 1994. p. 271-283.

SALVARO, Giovana I. J. Ainda precisamos avançar: os sentidos produzidos por trabalhadoras/es rurais sobre a divisão sexual do trabalho em um assentamento coletivo do Movimento dos Trabalhadores Rurais (MST) em SC. 2004. Dissertação (Mestrado em Psicologia) - Universidade Federal de Santa Catarina, Florianópolis.

SIQUEIRA, Maria Juracy Toneli. "Novas formas de paternidade: repensando a função paterna à luz das práticas sociais". In: SILVA, Alcione L.; LAGO, Mara C. de Souza; RAMOS Tânia R. O. Falas de gênero: teorias, análises, leituras. Florianópolis: Editora Mulheres, 1999. p. 187-201. 
SILVA, Cristiani B. As fissuras na construção do "novo homem" e da "nova mulher": relações de gênero e subjetividades no devir MST - 1979-2000. 2003. Tese (Doutorado em História) - Universidade Federal de Santa Catarina, Florianópolis.

SOUZA-LOBO, Elisabeth. A classe operária tem dois sexos: trabalho, dominação e resistência. São Paulo: Brasiliense, 1991.

VYGOTSKI, Lev S. Pensamento e linguagem. São Paulo: Martins Fontes, 1987.

\section{Workdays of Men and Women in a Collective Settlement of the Landless Movement (MST)}

Abstract: This text presents a discussion on the division of labor in a collective settlement of the Landless Movement (Movimento dos Trabalhadores Rurais Sem Terra - MST) in Santa Catarina, characterized by the collectivization of land and of all means of production. Within this form of organization and according to the directives established by the MST, an equalitarian and solidarious transformation of society, including the construction of new genre relations, is sought for. What has been noted, throughout the daily routine, is that men and women alike, both historical and cultural subjects, appropriate this discourse at the same time in which they try to deal with upcoming contradictions. Within the latter, and based on fixed relational standards, different work hours are thus established. Men are determined to work on a daily eight hour basis in production whereas women, due to domestic work and child rearing, are granted a four hour schedule.

Key words: collective settlement, gender relations, sexual division of labor, daily workdays and hours. 